\title{
TEMA LIVRE
}

\section{Impedido! As configurações de gênero na repercussão da contratação do Robinho pós condenação por violência sexual}

\author{
Camila Muhl ${ }^{1}$ \\ Jessika Karine Biscouto ${ }^{2}$ \\ Isis Barbosa Vidal ${ }^{3}$ \\ Bianca Beatriz Pereira ${ }^{4}$
}

Resumo: O jogador Robinho foi condenado em primeira instância em 2017 por violência sexual contra uma jovem albanesa na Itália. Em 2020, quando o time Santos Futebol Clube anuncia a sua contração, o caso volta à tona e vira alvo de debates na arena pública. O presente artigo tem como objetivo investigar a repercussão da contratação do jogador e posterior suspensão do contrato através dos comentários nas redes sociais. Para tal, a Análise de Conteúdo foi acionada para avaliar 2000 comentários realizados na página oficial do clube no Facebook, a partir dos quais se construiu as quatro categorias de análise: Percepções sobre o jogador; Percepções sobre a contratação; Machismo e A dialética entre a Masculinidade Hegemônica e a Masculinidade Cúmplice. Compreender as interações sociais envolvidas na repercussão deste caso permitiu compreender as configurações de gênero presentes na arena do futebol brasileiro.

Palavras-chaves: Gênero; Violência de Gênero; Violência Sexual; Masculinidades; Futebol.

\section{Introdução}

O futebol pode ser visto como um símbolo da identidade nacional brasileira e acaba por reproduzir as relações sociais existentes em nosso país, as hierarquias, as

\footnotetext{
${ }^{1}$ Doutora em Sociologia pela Universidade Federal do Paraná. Mestra em Psicologia pela Universidade Federal do Paraná. Psicóloga pela Universidade do Oeste de Santa Catarina. Professora da FAE Centro Universitário. E-mail: came.muhl@gmail.com

${ }^{2}$ Aluna do curso de Psicologia da FAE Centro Universitário. Bolsista do Programa de Apoio à Iniciação Científica (PAIC 2020/2021). E-mail: jessika.biscouto@mail.fae.edu

3 Aluna do curso de Psicologia da FAE Centro Universitário. Integrante do Programa de Apoio à Iniciação Científica (PAIC 2020/2021). E-mail: isis.barbosa@mail.fae.edu

${ }^{4}$ Aluna do curso de Psicologia da FAE Centro Universitário. E-mail: bianca.beatriz@mail.fae.edu
}

Vol. 03, N. 13, Jan. - Abr., 2021 - http://periodicoscientificos.ufmt.br/ojs/index.php/rebeh/index 
desigualdades, as crenças, as ideologias, as disputas políticas, os aspectos econômicos, entre outros, se tornando um lócus importante de sociabilidade e construção da subjetividade (TOLEDO, 1993; MURAD, 2013).

Grosso modo, quando se fala de futebol no Brasil, não é só do jogo que se está falando. O futebol funciona como uma arena reduzida que representa os fenômenos da sociedade, assim, ao fazer uma análise das práticas em torno do futebol no país é possível compreender os conflitos e as tensões presentes na sociedade brasileira (PINTO; ALMEIDA, 2014).

No mês de outubro de 2020, o futebol brasileiro, e o país todo, é tomado por uma polêmica: a contratação do jogador Robinho pelo Santos Futebol Clube, mesmo depois da sua condenação por violência sexual na Itália. Esse episódio traz em si a amálgama de gênero de nossa sociedade, onde estão representadas as masculinidades, feminilidades e, também, a violência de gênero.

Connel (1995, p. 188) define a masculinidade como "uma configuração de prática em torno da posição de homens na estrutura das relações de gênero". Assim, cabe perguntar, que prática de masculinidade é essa que se desenrola na violência sexual? Para a autora, toda prática é uma ação que possui uma racionalidade e um significado histórico, ainda que nem toda prática seja necessariamente racional. Nesse sentido, não se pensa a violência de gênero nem como um ato racional nem como uma explosão insensata, mas sim como uma ação competente, propositada e que tem como objetivo a manutenção da supremacia masculina (CONNEL, 1995).

O presente artigo tem como objetivo analisar a repercussão social da contratação do jogador Robinho após a sua condenação por violência sexual na Itália desde os estudos de gênero. Para tal, foram escrutinados os comentários realizados na página oficial do Santos na rede social Facebook, através da análise de conteúdo proposta por Bardin (1977). Os resultados encontrados foram apresentados em quatro categorias: Percepções sobre o jogador; Percepções sobre a contratação; Machismo e A dialética entre a Masculinidade Hegemônica e a Masculinidade Cúmplice.

\section{O caso Robinho}


No dia 10 de outubro de 2020, o Santos fechou a contratação do atleta Robson de Souza, popularmente conhecido como Robinho, que faria a sua quarta passagem pelo clube onde já havia ganhado títulos e era ídolo da torcida. Na mesma semana do anúncio da contratação, voltaram a mídia notícias sobre o processo judicial que o jogador enfrentava na justiça italiana, bem como foram divulgadas informações sobre as investigações e a transcrição de áudios coletados no processo que foram considerados incriminadores (FERRAZ, 2020; GIUFRIDA, 2021).

O processo em questão fala de uma situação ocorrida em 2013 em uma boate de Milão, em que uma jovem de origem albanesa apresentou queixa contra o jogador e seus amigos por violência sexual. Robinho foi condenado em primeira instância pelo crime em 2017 e teve a condenação confirmada em segunda instância em 2020 pela Justiça Italiana. O jogador nega que o crime tenha ocorrido e alega sexo consensual (FERRAZ, 2020; GIUFRIDA, 2021).

Com a repercussão negativa na mídia, descontentamento por parte de uma parcela dos torcedores e pressão dos patrocinadores, o clube suspendeu o contrato do jogador no dia 16 de outubro de 2020, conforme a nota oficial: "O Santos Futebol Clube e o atleta Robinho informam que, em comum acordo, resolveram suspender a validade do contrato firmado no último dia 10 de outubro para que o jogador possa se concentrar exclusivamente na sua defesa no processo que corre na Itália." (FERRAZ, 2020; GIUFRIDA, 2021).

\section{Masculinidades dentro do contexto futebolístico}

Quando pensamos em futebol brasileiro e na masculinidade encontrada neste contexto, percebemos uma padronização de comportamento dos homens que são parte deste mundo futebolístico, seja como dirigentes, técnicos, jogadores, torcedores ou mídia esportiva, é fácil de perceber que um tipo hegemônico de masculinidade é conformado, esperado e aceito. Connell e Messerschmidt em seu estudo sobre a masculinidade hegemônica, nos explicam: 
A masculinidade hegemônica foi entendida como um padrão de práticas (i.e., coisas feitas, não apenas uma série de expectativas de papéis ou uma identidade) que possibilitou que a dominação dos homens sobre as mulheres continuasse. A masculinidade hegemônica se distinguiu de outras masculinidades, especialmente das masculinidades subordinadas. A masculinidade hegemônica não se assumiu normal num sentido estatístico; apenas uma minoria dos homens talvez a adote. Mas certamente ela é normativa. Ela incorpora a forma mais honrada de ser um homem, ela exige que todos os outros homens se posicionem em relação a ela e legitima ideologicamente a subordinação global das mulheres aos homens. (CONNELL; MESSERSCHMIDT, 2013 p. 215).

No mesmo estudo, os autores ainda ressaltam que a masculinidade hegemônica depende do contexto histórico-cultural na qual está inserida, e por esse motivo está passível de mudanças na sua constituição e reconstrução, pois tanto "no nível local como nos níveis societais mais amplos, as situações nas quais as masculinidades foram elaboradas mudam ao longo do tempo" (CONNELL, MESSERSCHMIDT, 2013, p. 263).

Falar sobre um tipo hegemônico de masculinidade, nos leva a entender que outras masculinidades existem. Podemos citar a masculinidade subordinada que fala da hierarquia entre os grupos de homens, onde, por exemplo, os heterossexuais ocupam um lugar de dominação em relação aos homossexuais. A masculinidade cúmplice é aquela que se identifica com os padrões da masculinidade hegemônica e ainda que não possua todos os elementos que a colocariam no grupo dominante, consegue usufruir de algumas vantagens do patriarcado. Por último, temos a masculinidade marginalizada, que agrupa aqueles que possuem uma caraterística subalterna por raça ou classe, por exemplo (CONNEL, 1995; CONNELL, MESSERSCHMIDT, 2013).

No contexto brasileiro, a masculinidade hegemônica está ligada ao futebol. De acordo com Dias e Gomes (2020), o futebol é um esporte muito popular no país e muitos meninos crescem desejando uma carreira de jogador profissional de futebol, e mesmo que não consigam, tornam-se torcedores, ou seja, é muito comum desde cedo, crianças frequentarem estádios e torcidas e com isso ver como normal a ideia de masculinidade encontrada ali.

Isso pode ser explicado em parte porque a participação em jogos e competições é um traço característico do que se espera do gênero masculino nas culturas ocidentais, não por isso ser uma essência universal ou uma característica biológica, mas sim porque

Vol. 03, N. 13, Jan. - Abr., 2021 - http://periodicoscientificos.ufmt.br/ojs/index.php/rebeh/index 
a competição é frequentemente enfatizada na formação masculina. Desde a escola, os meninos são incentivados a se desafiarem e aprendem que tornar-se um adulto bemsucedido implica vencer, ser o melhor em algo. O mesmo processo não acontece com as meninas, já que não há identificação entre feminilidade e competitividade. Para aqueles homens que desejam a vitória, um caminho possível é o esporte, sendo que no Brasil destaca-se o futebol, que passa a ser visto como um interesse masculino quase obrigatório (LOURO, 2000; GASTALDO, 2005).

Nesse sentido, é possível perceber como as relações entre futebol e masculinidade começam a ser forjadas desde cedo, ainda na infância, o que impacta na construção da subjetividade dos sujeitos, que vão ter suas identidades forjadas em relação aos valores da sociedade em que habitam. Destarte, o universo dos esportes vai ter um impacto direto na forma como os homens brasileiros se percebem e se comportam, haja vista estarem imersos em valores como a potência e a virilidade. (PINTO; ALMEIDA, 2014; TOLEDO, 1993; HOLLANDA; AZEVEDO; QUEIROZ, 2014).

\section{Método}

A pesquisa na internet tem sido cada vez mais utilizada já que a interação online exemplifica as experiências sociais desenvolvidas neste momento histórico particular e complexo que vivemos, onde as trocas no ambiente online trazem camadas extras de significado para o objeto de pesquisa. A análise realizada a partir das redes sociais, como a feita neste estudo, permite a compreensão de uma sociedade que se estrutura em rede e a interação entre os sujeitos (FRAGOSO; RECUERO; AMARAL, 2011).

Para investigar a repercussão da contratação do jogador Robinho após a condenação por violência sexual escolhemos a postagem da nota oficial do Santos sobre a suspenção do contrato, postada no dia 16 de outubro, na página do Facebook do clube. A postagem, acima apresentada, foi escolhida por trazer conteúdo específico sobre a condenação quando diz que o afastamento é motivado para que o jogador se concentre na sua defesa. No dia 26 de outubro, dia em que realizamos a coleta de dados, a presente postagem já possuía 8 mil comentários, 5,6 mil compartilhamentos e 23 mil interações 
(curtidas). A título de comparação, postagens do mesmo período possuíam um engajamento muito menor: postagem do dia 24 de outubro sobre partida do time feminino contava com 107 comentários, 50 compartilhamentos e 3,4 mil interações; postagem de 23 de outubro em comemoração ao aniversário de Pelé possuía 892 comentários, 1,1 mil compartilhamentos e 21 mil interações; e postagem do dia 20 de outubro sobre a vitória em jogo da Libertadores possuía 1,8 mil comentários, 3,1 mil compartilhamentos e 35 mil interações.

Para compor o corpus deste estudo, coletamos os primeiros 2000 comentários $^{5}$ feitos na referida postagem que foram tratados segundo a Análise de Conteúdo proposta por Bardin (1977). Neste modelo, a análise organiza-se em: 1) Pré-análise; 2) Exploração do material e 3) Tratamento dos resultados, inferência e interpretação. Dos 2000 comentários, excluímos aqueles que não se conectavam com o objetivo do artigo por trazerem conteúdos como: links, xingamentos, imagens e provocações entre times, sendo incluídos na análise um total de 873 comentários.

Para o tratamento dos dados, estabelecemos duas categorias temáticas a priori: percepções sobre o jogador e percepções sobre a contratação. Após a leitura exaustiva do material, outras duas categorias a posteriori foram acrescentadas: machismo e a dialética entre a Masculinidade Hegemônica e a Masculinidade Cúmplice. A análise temática permite descobrir os núcleos de significado que aparecem em relação ao objeto escolhido, bem como, as motivações, opiniões, atitudes, valores, crenças e tendências sobre o tema (BARDIN, 1977)

Fragoso, Recuero e Amaral (2011) reforçam que a pesquisa na internet, através da internet ou a respeito da internet traz desafios éticos específicos, em especial, para a coleta dos dados. No corpus desta investigação utilizamos apenas dados públicos, que se encontravam abertos e disponíveis para todos, em uma plataforma que as pessoas que a utilizam sabem da sua publicidade. Ainda assim, para proteger a privacidade e a integridade individual, omitimos os nomes dos participantes, substituindo por números e fizemos a transcrição do texto para não utilizar a postagem original.

\footnotetext{
5 Dos comentários selecionados para análise, 1528 comentários foram feitos por homens, 467 comentários feitos por mulheres e de 5 comentários não foi possível inferir gênero pois se tratavam de perfis de personagens de ficção, empresas ou casal (duas pessoas dividam o perfil).
}

Vol. 03, N. 13, Jan. - Abr., 2021 - http://periodicoscientificos.ufmt.br/ojs/index.php/rebeh/index 
Percepções sobre o jogador

Nesta categoria, analisamos a direção qualitativa dos comentários, tal seja, um estudo de favoritismo/desfavoritismo (BARDIN, 1977). Os comentários que se posicionam de forma desfavorável ao jogador contaram 412 entradas e aqueles que são favoráveis somaram 265 comentários. Como exemplo do lado desfavorável ao jogador temos afirmações como "Para mim não deve ser tratado como jogador e sim com o nome que the cabe, estuprador" (Comentário 1209, mulher) e a hashtag "\#SantistaContraRobinho" (Comentário 199, mulher). Já do lado favorável houve comentário como "Torcendo pelo livramento do Robinho" (Comentário 1896, mulher) e a hashtag "\#fechadocomrobinho" (Comentário 1254, homem).

Entre aqueles que se posicionaram favoravelmente ao jogador, um sentido importante que surge é o fato de o processo não ter terminado, assim, haveria uma chance de inocência e seria possível manter a confiança no comportamento adequado do homem:

"Quantas pessoas já foram condenadas em primeira instância e na última foram inocentadas" Comentário 38, homem

“Ainda está em julgamento, não é decisão definitiva” Comentário 69, homem

"Condenação só existe quando transitada em julgado. Até que isso aconteça, a presunção total é de inocência, tanto nas leis da Itália quanto no Brasil. Lei é lei e isso não se discute." Comentário 118, homem

"Tão acabando com a vida do cara sem nem o processo terminar" Comentário 844, homem

"Como vamos repudiar um ato que ainda não teve seu julgamento final?" Comentário 624, homem

"Vamos esperar a sentença final, acredito na inocência do Robinho" Comentário 1165, homem

“Acredito que ele seja inocente” Comentário 1993, homem

A honra masculina é um valor presente que ajuda a estruturar a identidade dos homens e remete aos duelos pela honra que aconteciam no século XVIII e XIX (ZANELLO, 2018). Quando os comentadores defendem a inocência de Robinho, o fazem porque existem estruturas sociais que não permitem que se questione a honra de um homem, bem como, asseguram que essa honra deve ser defendida, em especial, 
quando o detrator é uma mulher, já que existe uma cultura de cumplicidade, como afirma Zanello (2018), onde um homem deve lealdade para com os outros homens.

Outra estratégia que surge é a tentativa de desabonar o processo e o crime. Questiona-se a vítima, o ocorrido, as provas, a condução do caso pela justiça.

\footnotetext{
"[como se fosse] impossível se passar por ele em áudio de app né" Comentário 39, homem

"não é passando pano para o Robinho e nem ficando contra ele, mas esse bagulho de 'ficar do lado da vítima' meio que já deu ruim para uma galera porque estavam errados" Comentário 42, homem

"Será que o vazamento não é fake? Nosso jornalismo costuma distorcer e fabricar noticias." Comentário 237, homem

"Tem provas?" Comentário 293, homem

"Você viu? É testemunha?" Comentário 796, homem

"Será que foi estupro mesmo? Ou ela foi sabendo de todas as safadezas que iria rolar nesse lugar?" Comentário 722, perfil de casal

"Eu também odeio estuprador... se eu pudesse eu matava todos..., mas será que isso não foi mais um golpe desta Maria Chuteira?" Comentário 869, homem

"Estão fazendo tempestade em um copo de água" Comentário 1800, homem
}

Para compreender as configurações de gênero presentes nesses comentários é preciso lembrar que cada sociedade tem ideias, preconceitos, valores, normas, deveres, proibições e interpretações distintas para homens e mulheres que se originam na cosmovisão de gênero que opera nesse território (LAGARDE, 1996).

La representación del orden genérico del mundo, los estereotipos sociales y sus normas, son fundamentales en la configuración de la subjetividad de cada quien y en la cultura. Se aprenden desde el principio de la vida y no son aleatorios, son componentes del propio ser, dimensiones subjetivas arcaicas y em permanente renovación, por ello son fundantes. Están en la base de la identidad de género de cada quien y de las identidades sociales asignadas y reconocidas al resto de las personas (LAGARDE, 1996, p. 18).

Dada a concepção androcêntrica que rege a cultura ocidental, onde o homem é a medida de todas as coisas e hierarquicamente superior na disputa de poder ${ }^{6}$, é natural que em um caso de antagonismo violador/homem versus vítima/mulher, a balança penda mais favoravelmente ao homem, pois há uma confiança tácita no masculino. Por

\footnotetext{
${ }^{6}$ Para Lagarde (1996), a ordem fundada a partir da sexualidade é desde o início uma ordem de poder, assim sendo, a divisão entre os gêneros é distinta, bem como as oportunidades e restrições que lhe são impostas socialmente.
}

Vol. 03, N. 13, Jan. - Abr., 2021 - http://periodicoscientificos.ufmt.br/ojs/index.php/rebeh/index 
outro lado, para a mulher, esse ser tido como emocional, irracional e fraco, sobram os questionamentos: será que aconteceu como ela falou? Será que foi golpe? Será que ela não está mentindo?

Aqueles que comentaram favoravelmente ao jogador buscaram justificar os seus comentários utilizando especialmente dois argumentos: a) a história pregressa com o time e b) a possibilidade de outras pessoas alheias serem atingidas pela repercussão.

\footnotetext{
"Vamos parar de taca pedra no cara. Vamos ficar com a imagem de Robinho menino da vila que tirou o peixe da fila" Comentário 1721, homem

"Robinho é idolo!!!!" Comentário 34, homem

"O cara tem família e filho pequeno. Isso é injusto o que vocês estão falando" Comentário 1880, homem
}

Olhando para esses comentários, podemos pensar em como o homem é medido por sua eficácia laboral, ou seja, sua capacidade de ser trabalhador e provedor da família, isso faz dele um "verdadeiro" homem. Da mesma forma, o homem também é medido pela sua eficácia sexual, assim, na situação em que além de ser casado ele desenvolve relações sexuais fora do casamento, isso também lhe qualifica como um "verdadeiro" homem, dada a sua conduta de comedor (ZANELLO, 2018). Todavia, Bola (2020) lembra que a ideia de que exista um "homem de verdade" é um mito, que serve apenas para classificar os homens, incluindo alguns em categorias privilegiadas, enquanto exclui os demais.

Nos deslocando agora para o outro polo da discussão, entre aqueles comentários desfavoráveis ao jogador, percebemos dois sentidos emergindo, o primeiro fala sobre a importância do jogador de futebol na sociedade brasileira e a preocupação como a índole das pessoas que deveriam ou não ocupar o lugar de ídolo, já o segundo sentido fala sobre como a situação analisada transcende o futebol, uma vez que a violência sexual é um problema de grandes proporções e consequências.

Vamos primeiramente observar os comentários que versam sobre o papel desempenhado pelo jogador de futebol e quais são as ações esperadas dele:

\footnotetext{
"Uma coisa é ser apaixonado pelo time, pela camisa, outra é proteger estuprador" Comentário 758, homem

"Robinho meu ídolo em 2002, chorei de emoção ao ver desfilar em campo seu futebol contagiante, mas hoje as coisas tomaram outros rumos e meu
}

Vol. 03, N. 13, Jan. - Abr., 2021 - http://periodicoscientificos.ufmt.br/ojs/index.php/rebeh/index 
idolo pode ser um ser desprezivel, e se condenado, não gostaria que meu filho veja como ídolo" Comentário 1292, homem

"Torcedor de verdade é aquele que quer ver apenas homens íntegros e certos representando o clube, e não defensores de estuprador \#forarobinho" Comentário 1437, homem

"Gente decente não comete violência sexual" Comentário 880, mulher

"Esse jogador fracassado vai se aposentar e sair do futebol pela porta dos fundos que é o que ele merece" Comentário 175, mulher

"[...] pessoas vazias que só veem pelo lado dele ser um ótimo jogador, ele sendo um estuprador é o de menos como podemos ver" Comentário 71, mulher

"Não tenho como ídolo uma pessoa condenada por estupro, tenho respeito pela minha mãe e pelas outras mulheres da minha familia, se eu idolatro um cara desses, como fica para elas?" Comentário 40, homem

"Ele não pode ser símbolo de nada. Ele precisa pagar pelo que fez e viver no anonimato para o resto da vida. Tem muitas profissões que são dignas e não são símbolo por aí." Comentário 153, mulher

O futebol é uma manifestação cultural que no Brasil tem grande importância no imaginário social e que já foi palco de inúmeras manifestações que transcendem a bola rolando, como as lutas sociais e democráticas e os embates contra o elitismo e as exclusões estruturais e históricas da formação social brasileira (MURAD, 2013). É na esteira dessa compreensão que o futebol impacta na vida das pessoas que os comentários acima buscam retirar desse palco uma pessoa condenada por violência sexual, entendendo que ela não deveria estar sob os holofotes, recebendo as glórias que a vitória sobre o time adversário traz.

Passamos agora para os comentários que focam na violência contra a mulher, pedindo para que o futebol seja deixado em segundo plano.

\footnotetext{
"A sociedade tem que dar uma resposta. A violência contra a mulher já passou de todos os limites. O cara não pode fazer o que fez e continuar como se nada tivesse acontecido. É a vida da mulher, ela nunca mais será a mesma" Comentário 153, mulher

"Leu a parte em que o próprio Robinho confessa o que fez? Ele confessa o crime que cometeu. Se você leu e continua duvidando da vítima, sinto muito por você. Se ela é santa ou não, não interessa. O que ela é ou não, não interessa. Pq nada justifica um estupro, nem a roupa da vítima, nem o lugar e nem a hora. Nada justifica um estupro. Só acontece estupro pq existe o ESTUPRADOR." Comentário 864, mulher

"O fato de a vítima se enquadrar no perfil de Maria Chuteira não concede aos agressores o direito de estuprá-la, estando ela consciente ou não" Comentário 989, homem

"Eu sou corintiano e acho que a questão nem é do futebol, mas de pensar na moça que foi abusada, o futebol cega tanto as pessoas que eles defendem um estuprador com unhas e dentes, é o fim do mundo mesmo" Comentário 1444, homem
} 
A violência de gênero é uma realidade inquietante no Brasil. Em 2019, ocorreram 1.326 feminicídios no país, bem como foram registrados 266.310 casos de lesão corporal de mulheres por violência doméstica e expedidas 349.942 medidas protetivas no âmbito da Lei Maria da Penha, segundo os dados do Anuário Brasileiro de Segurança Pública (2020). Esses dados demonstram como a violência contra as mulheres tem sido normalizada como um aspecto estrutural das relações de gênero (FEDERICI, 2019).

Tiburi (2019) utiliza a imagem de uma equação para pensar esse fenômeno, de um lado estão os homens e o poder e de outro lado, estão as mulheres e a violência, sendo o poder exercido pelos homens que garante o exercício da violência contra as mulheres. Os comentários acima vão na direção de denunciar essa situação que subjuga as mulheres no ato violento e não questiona a dominação exercida pelos homens, em especial, aqueles que têm mais poder por se enquadrarem na masculinidade hegemônica.

A autora bell hooks (2020) fala sobre como a maioria das pessoas se posiciona contra o espancamento de mulheres e crianças ou contra a violência sexual, mas isso não necessariamente retrata que essas pessoas entendam a relação existente entre violência de gênero e os valores patriarcais e sexistas da sociedade pois isso significaria ter que desafiar e mudar as maneiras tradicionais de como se pensa o gênero. Todavia, essa tarefa é urgente, pois acabar com a violência de gênero depende de acabar com o sexismo.

\section{Percepções sobre a contratação}

As duas direções da discussão nessa categoria - aqueles que consideram que a contratação do jogador deveria ser feita (30 comentários) e aqueles que discordam (166 comentários) - parecem estar de acordo com o fato de que o crime aconteceu, assim os que desaprovam Robinho jogar no Santos o fazem por causa do processo em andamento e aqueles que desejam o jogador no time o fazem apesar do processo em andamento. Vejamos os comentários contrários a contratação: 


\footnotetext{
"Você viu a transcrição da conversa dele? Se por acaso ele conseguir se safar de uma condenação, o que eu não acredito, mesmo assim não dá para aceitá-lo como jogador" Comentário 182, mulher

"[...] conduta reprovável, embora legal, do clube em associar-se a alguém com esse histórico." Comentário 183, mulher

"O mínimo que se esperaria é nem ter contratado. Qual empresa do mundo contrata um condenado em primeira instância por violência sexual?" Comentário 309, homem

"Se fosse um time sério não contratava monstros e não dispensava por pressão" Comentário 313, homem

"Jogador nenhum está acima da violência contra as mulheres" Comentário 639, homem

"No meu time não quero representante estuprador" Comentário 792, mulher

"Sério que tem gente que queria um condenado por estupro jogasse no seu time?" Comentário 922, mulher

"Não se compactua com estupro, isso não é mais aceitável na sociedade, $e$ sempre haverá pressão quando houver uma tentativa de normalização desse tipo de atrocidade. Tem craque a vontade para vcs contratarem." Comentário 957, mulher

"Não deveriam nem ter cogitado contratar um jogador com essa acusação. Falta de respeito com a história do Santos e falta de noção" Comentário 1601, homem

"Pela primeira vez em muito tempo tive vergonha do time que torço. Espero que isso não volte a acontecer e que façam mudanças no estatuto para proibir sequer de negociar com jogadores envolvidos em processos criminais que envolvam violência de qualquer tipo" Comentário 1788, homem
}

Os comentários parecem convergir na direção de que o comportamento violento não é aceitável, bem como, o clube contratar um homem com esse comportamento não é admissível. Entre os comentários, destacamos aqueles que olham para o time como um ambiente corporativo, exigindo postura ética e procedimentos legais para avaliar as contratações para além do desempenho profissional. Não se questiona que ele seja um bom jogador, mas o que acontece extracampo interfere na forma como ele vai executar as suas funções, como vai conviver com os outros membros da equipe e impacta no conjunto de pessoas que se relaciona com o time de alguma forma.

Entre aqueles comentários contrários a contratação, houve os que apresentaram o motivo "mulheres" para justificar, questionando como seriam impactadas as torcedoras e as jogadoras do time feminino do clube pela presença do Robinho no Santos:

\footnotetext{
“o que mais tem é prova e uma confissão do próprio, quer mais o que? Tudo isso para não acreditar que uma mulher foi estuprada? Que santista é vc que não respeita as mulheres que estão na arquibancada torcendo pelo time? Não só nós torcedoras, mas todas as mulheres. Tira a camisa do time pq vc
}

Vol. 03, N. 13, Jan. - Abr., 2021 - http://periodicoscientificos.ufmt.br/ojs/index.php/rebeh/index 
ainda não entendeu que futebol é mais que apenas homens correndo atrás da bola" Comentário 23, mulher

"Lamentável para as torcedoras e lamentável para todas as mulheres!!" Comentário 1097, mulher

“[...] não quero no meu time pelo Santos ter um time feminino." Comentário 130, homem

"Não adianta nada o clube fazer campanha contra a violência feminina e ter um jogador acusado por estupro no elenco" Comentário 814, homem

Ao realizar uma divisão sexista da realidade entre homens e mulheres, como se os gêneros constituíssem esferas separadas, os comentários apontam que o maior dano com a contratação seria trazido as mulheres, o que nos leva a perguntar: se as mulheres aí citadas não existissem, a contratação deixaria de ser um problema? Esses posicionamentos parecem ser construídos sobre a perspectiva que violência sexual é um problema de mulher (o que não é verdadeiro pois no ano de 2019, segundo o Anuário Brasileiro de Segurança Pública, 14,3\% das vítimas de estupro ou estupro de vulnerável eram homens e meninos), colocando a vítima como o centro do problema e não o abusador.

Todavia, o argumento de invocar a mãe ou a filha para se manifestar diante de uma situação de sexismo não é de todo negativo, pois, como argumenta Connel (1995), existem redes de relações que conectam homens e mulheres, que quebram a lógica da “esfera separada". Nesse cenário, são muitas vezes as relações pessoais que disparam o interesse masculino em se juntar a uma luta por justiça social de gênero.

Entre aqueles que defendem a contratação do jogador, a acusação de crime não parece ser um problema, desde que ele ajude o time:

"O cara foi condenado, que fique bem claro, eu não estou defendendo a atitude dele. Como ser humano vcs podem julgar a atitude dele, tudo bem. Agora como jogador dentro das quatro linhas ele é um dos maiores ídolos do time. Concorda? Então falar que o cara não tem moral ou dignidade de vestir a camisa do clube, acho isso um exagero." Comentário 110, homem "ele não pode trabalhar enquanto isso? Se ele está solto" Comentário 151, homem

“O que importa é ajudar em campo." Comentário 292, homem

"Robinho ia ajudar muito o clube nesse momento dificil” Comentário 348, homem

"Eu acho que ele tem o direito de trabalhar sim, ele tem o direito de se defender sim, enquanto a justiça não condenar ele e não mandar prender, ele tem o direito de liberdade, ele não é procurado nem foragido então sendo assim não vejo erro do clube em repatria-lo" Comentário 748, homem 
"O Santos deveria contratar o Robinho sim, pois o mesmo ainda não foi condenado em definitivo por estupro. E boquete não tem como ser forçado, a não ser como arma apontada, o que parece, não foi o caso né? " Comentário 1604, homem

"Perder um jogador como o Robinho para mim é uma pena" Comentário 1777 , homem

"Fizeram errado, deveriam ter mantido o Robinho até o processo acabar" Comentário 1786, homem

Os argumentos aqui giram em torno da ideia de que ele pode ajudar o clube nas partidas e que ele teria o direito de trabalhar já que não está preso, falando, portanto, da sua atuação enquanto jogador de futebol. A solicitação então é que se diferencie o pessoal do profissional, o público do privado:

\footnotetext{
"O clube contrata o atleta e não a vida pessoal dele" Comentário 1813, homem

"O que nós quer do cara é o futebol dele e não o caráter, nem o casamento, nem as zonas que ele vai nem nada, só o futebol... do resto, não interessa” Comentário 1136, homem

“[...] ele é digno de vestir a camisa do time sim, já deu muito por nós, que pague pelos erros dele se cometeu, jamais podemos misturar o profissional com o pessoal, entendam isso." Comentário 12, homem

"Se trata de um dos maiores ídolos do Santos dentro de campo, o que aconteceu fora de campo é problema da justiça e ele” Comentário 738, homem
}

Ao fazer uma análise histórica das questões de gênero, essa solicitação não é infundada pois o público sempre foi o lugar do homem, enquanto a mulher cabia o privado, desde a Grécia Antiga (LAMOUREUX, 2009, ZANELLO, 2018). Aqui acontece então uma reencenação dessa dinâmica: ao homem o holofote dentro das quatro linhas do campo de futebol e o silêncio sobre o que acontece na intimidade, ainda que o que tenha acontecido no privado seja a violência contra uma mulher.

Esta situação remete a afirmação oriunda do senso comum ouvida em casos de violência de gênero: "em briga de marido e mulher não se mete a colher", que fala justamente das ações que ocorrem no ambiente privado e que autorizam e naturalizam o homem violento, pois o que acontece nessa esfera não é de interesse público. São situações como essa que levam o movimento feminista a afirmar que o privado é político, no sentido de que as relações dominação e violência que ali ocorrem precisam 
ser visibilizadas para serem combatidas. $\mathrm{O}$ acesso à cidadania plena das mulheres passa pela reformulação da esfera pública e da esfera privada (LAMOUREUX, 2009).

\section{Machismo}

Compreendemos por machismo as atitudes individuais que espelham o sistema social patriarcal notadamente marcado pela dominação masculina e crença na superioridade dos homens (DELPHY, 2009; TIBURI, 2019). Não existe uma forma única do machismo se manifestar, podendo ocorrer desde a depreciação de uma mulher, a misoginia e mesmo atos discriminatórios, como aqueles encontrados no mercado de trabalho que fazem a mulher ganhar menos e não avançar na carreira.

Nos comentários analisados, muitas vezes a vítima da violência sexual foi alvo de manifestações machistas:

\footnotetext{
“Ninguém é santo nessa história, nem a suposta vítima" Comentário 89, homem

"Essa mulher foi lá [na boate] para rezar ou foi para transar?" Comentário 92, homem

"Essas Marias Chuteiras não podem ver um jogador de futebol com milhões, um cantor famoso, cara com milhões ai elas enchem o rabo de pinga, dá nisso, falam que foi estuprada." Comentário 305, homem

"Putas e Marias Chuteiras que querem arrancar dinheiro sem trabalhar" Comentário 1070, homem
}

A antropóloga Marcela Lagarde (2005) propõe que as mulheres estão cativas a sua condição de gênero num mundo patriarcal, sendo que esses cativeiros se referem a determinados papéis de gênero que são esperados das mulheres e que as prendem na casa, no convento, no bordel ou no hospício. Nos comentários acima, podemos ver que é a figura da mulher puta que é acionada, a mulher que concretiza o desejo feminino culturalmente negado.

A puta cabe ofertar o seu corpo para realizar as fantasias eróticas dos outros, deve estar disponível para ser usada por homens diversos que não desenvolvem vínculos com elas, logo são descartáveis. Se por um lado, a puta é valorizada pelo prazer e o desejo que mobiliza, por outro, ela se afasta do cativeiro mais valorizado socialmente para as mulheres que é o de madresposa, que são virginais, castas, boas, 
fiéis (LAGARDE, 2005). Ao não desempenhar o papel de boa moça, a vítima é enquadrada pelos comentários como puta, assim, não poderia haver crime de violência sexual, uma vez que se envolver na relação sexual era o que se esperava dela, afinal, estava numa boate, bebendo, com homens desconhecidos, o que faz ela não se encaixar como madresposa e ser, portanto, o oposto disso: má, pecaminosa, traidora, não confiável.

Em outros momentos os comentários com conteúdo machista foram direcionados para qualquer mulher que fazia um comentário na postagem que desagrava os homens que estavam engajados na discussão. Os sentidos por trás desses comentários parecem ser as máximas de que mulher não entende de futebol, de que futebol não é lugar para mulher e que o espaço destas seria o lar, acionando novamente a imagem de madresposa, enquanto aquela que se doa em prol dos familiares, atendendo as necessidades de todos a sua volta:

\footnotetext{
“A louça já lavou?” Comentário 382, homem

"Vai arrumar a casa ao invés de vir falar mal do meu Santos porra" Comentário 459, homem

"tanque de roupa bem cheio para lavar, assim não tem tempo pra julgar sem ter conhecimento da causa" Comentário 488, homem

"A casa tá limpa?" Comentário 559, homem

"Sai do facebook moça, o arroz vai queimar..." Comentário 622, homem "É uma mal amada" Comentário 444, homem

"Mulher e futebol, palavras que não combinam" Comentário 789, homem

"Quem é o goleiro do Santos e o lateral esquerdo? Você nem sabe! Cale a boca" Comentário 1881, homem

"Petição pras mulheres só falarem quando um homem pedir; Copia e cola com o seu nome embaixo" Comentário 611, homem
}

Federici (2019) aponta que a adesão da mulher aos papéis no casamento e de procriação, bem como, desempenhar a obediência ao marido, sempre foram os pilares de moralidade que sustentam a maioria das sociedades. Às mulheres competem, segundo a autora, se conformar ao que se espera delas: a feminilidade assexuada, submissão, resignação e subordinação ao mundo masculino. Também cabe à mulher aquela esfera de atividades que foram completamente depreciadas pelo capitalismo, o cuidado do lar e das crianças.

Aqui aparece a ideia tão presente na tradição ocidental de um eterno feminino, enquanto a natureza imutável que as mulheres possuem que as tornam adequadas para Vol. 03, N. 13, Jan. - Abr., 2021 - http://periodicoscientificos.ufmt.br/ojs/index.php/rebeh/index 
algumas tarefas (ser mãe, esposa, cuidadora) e inadequadas para outras (aquelas no âmbito público). O eterno feminino, no entanto, não fala sobre a experiência vivida das mulheres, não fala sobre o que elas são, mas sim sobre o que deveriam ser, agindo como um dispositivo disciplinar que busca fixar as mulheres em posições subalternas (BERGOFFEN, 2020).

No núcleo de sentido dos comentários acima apresentados se conectam o cativeiro da madresposa com o lugar do privado que cabe a mulher. Aquelas que não se contentam em ser cativas e ficar no espaço restrito do lar tem a sua integridade atacada e são motivos de escárnio, seja porque foram a arena pública das redes sociais para se manifestar seja porque ousaram frequentar uma boate (LAGARDE, 2005; LAMOUREUX, 2009). Destaca-se ainda a avaliação negativa feita nos comentários por essas mulheres estarem se manifestando publicamente ou frequentando uma casa noturna, quando o mesmo não acontece quando os homens realizam essas ações, demonstrando o padrão duplo de gênero existente na sociedade em que se aplica um julgamento diferente para situações semelhantes quando elas envolvem homens e mulheres (GIDDENS, 1993).

Todavia, resta perguntar qual é o mecanismo que permite que essas mulheres sejam atacadas? Beauvoir (2016) fala do processo de alteridade que faz a mulher emergir enquanto o Outro diante do homem que representa a humanidade e o essencial, a mulher é determinada então pela negatividade, por não ser um homem e por todas as limitações que vem com esse fato. Nesse sentido, o homem é responsável por definir não só a si próprio, mas também a mulher, esse Outro que apresenta todas as características depreciativas que o distinguem do Mesmo.

\section{A dialética entre Masculinidade Hegemônica e Masculinidade Cúmplice}

Retomando a argumentação de Connel (1995), aprendemos que diferentes masculinidades são produzidas em um mesmo contexto social e que os homens estabelecem entre si relações de dominação, marginalização e cumplicidade. Nesse sentido, uma determinada forma hegemônica de masculinidade tem outras masculinidades agrupadas em torno dela, por exemplo, se tomamos como modelo de 
masculinidade hegemônica no Brasil aquela performada pelos jogadores de futebol, ao seu redor se formam outras práticas de masculinidade por aproximação ou diferença. Nessa categoria, a masculinidade que nos interessa é a cúmplice, os homens que não se enquadram na masculinidade hegemônica, mas ficam próximos o suficiente (ou desejam estar próximos) para se beneficiar dela.

A cumplicidade com o Robinho parece vir de um sentimento de "somos homens e é isso que fazemos mesmo", assim, não haveria nada de errado ou questionável na situação de violência sexual envolvendo o jogador:

\footnotetext{
“[...] somos homens, falamos sacanagem a todo momento... principalmente depois de um sexo com uma pessoa que ve não tem sentimento nenhum" Comentário 254, homem [sobre os áudios]

"Hoje flertar já está sendo usado como assédio" Comentário 371, homem

"Todo homem está sujeito a passar por isso, agora cabe a justiça julgar pq ninguém sabe o que realmente aconteceu" Comentário 727, homem

"Pelo que eu entendi aí tinha uma festinha e não parece em nada com estupro" Comentário 1448, homem
}

A condição de Robinho como um jogador de futebol bem-sucedido, famoso e rico, aparece para os outros homens como uma posição desejável, onde eles gostariam de estar se tivessem oportunidade. Connel (1995) nos recorda que ganhar a luta por hegemonia entre os grupos de homens, traz aqueles que ocupam a posição dominante vantagens materiais e psicológicas, o que faz com que outros homens também almejem estar nessa posição.

\footnotetext{
"Único problema é que Robinho não poderá mais visitar a Itália" Comentário 200, homem

"Esqueceu só de comentar que o fracassado é milionário. Queria ser fracassado como ele" Comentário 219, homem

"Essa mulherada ai está distribuindo para peão de obra, imagina para milionário" Comentário 753, homem

"Robinho pode tá sendo vítima de mais uma dessas pessoas que só querem tirar proveito do status e dinheiro do jogador" Comentário 784, homem

"Qual a certeza que vcs tem que a moça não fez isso porque quis e depois quis tirar uma grana do cara porque dinheiro para comer puta ele tem" Comentário 1129, homem

"Se en for estuprado que seja por um famoso, para eu pedir um dinheirinho e fazer meu pé de meia, igual essa rameira fez" Comentário 1155, homem

"Que sirva de exemplo para os jogadores, quando uma Maria Chuteira vier querer fazer orgia, corra" Comentário 1620, homem
} 
Nesses trechos são ressaltados alguns elementos sobre o tipo de vida que Robinho leva: fama, dinheiro, viagens. Connel (1995) afirma que existem emoções e prazeres que vem de um mundo generificado, assim, quando um homem houve as narrativas autobiográficas sobre o sucesso de homens com o esporte ou com carros, por exemplo, ele também passa a desejar ter esse prazer. Isso pode ser ainda mais intenso no caso dos esportes, onde há uma mídia específica no seu entorno, realizando uma promoção comercial desta masculinidade exemplar.

As masculinidades são construídas nas relações de poder desenvolvidas com mulheres, crianças, jovens e idosos, e, também, nas relações hierárquicas de homens com outros homens. Há sempre um valor comparativo dessas relações, o sucesso de um homem é medido em comparação a outros homens. São homens que avaliam e legitimam homens (KIMMEL, 1998; ZANELLO, 2018). Assim, observar a interação entre masculinidade hegemônica e masculinidade cúmplice permite compreender os comportamentos que são encorajados e aqueles que devem ser descartados.

É claro que a masculinidade não é uma essência constante e universal, mas sim uma coleção de significados e comportamentos fluidos. Todavia, em um determinado tempo e lugar, é possível reconhecer uma visão hegemônica de masculinidade, uma definição particular que é sustentada e reconhecida pelos outros homens (KIMMEL, 1998). Esse reconhecimento é importante, pois as masculinidades subalternas irão utilizar o modelo hegemônico para se medirem, assim, as ações de um jogador de futebol bem-sucedido, famoso e rico, podem acabar sendo espelhadas por outros homens na sociedade, mesmo que sejam ações de violência de gênero.

\section{Considerações Finais}

As reverberações do caso Robinho permitiram ver várias das configurações de gênero da sociedade brasileira sendo reencenadas: a violência de gênero, os papéis sociais atribuídos a homens e mulheres, o antagonismo entre público e privado, o sexismo, o machismo. Também mostrou como se constituem as masculinidades e feminilidades no contexto brasileiro, uma vez que os gêneros só existem em relação. Apontar e reconhecer esses fenômenos é importante, mas cabe lembrar que nem as 
feminilidades nem as masculinidades são estáticas (CONNEL, 1995; TIBURI, 2019), assim, o reconhecimento desta situação pode ser o primeiro passo para a mudança e a justiça social. O gênero é contraditório, já afirma Connel (1995), e é isso que cria a dinâmica histórica e impede que vivamos em uma reprodução eterna dos mesmos padrões de gênero.

Bola (2020) lembra como as performances de masculinidade representam e reforçam o que é considerado normal por aqueles que se identificam como homens, sendo que para a masculinidade hegemônica, a sua tendência à violência torna-se um comportamento esperado e incentivado (CONNEL, 1995). Investigar as formas como a sociedade se manifesta diante da masculinidade e da violência por ela causada traz contribuições para a compreensão das relações de gênero num determinado contexto social e o desenvolvimento de medidas para combater esse tipo de violência em específico.

\section{Referências}

BARDIN, Laurence. Análise de conteúdo. Lisboa: Edições 70, 1977.

BEAUVOIR, S. O segundo sexo. Rio de Janeiro: Nova Fronteira, 2016, vol. I.

BERGOFFEN, Debra. The Eternal Feminine. In: WEISS, Gail; MURPHY, Ann V.; SALAMON, Gayle. 50 Concepts for a Critical Phenomenology. Evanston, Illinois: Northwestern University Press, 2020. p. 121-126.

BOLA, JJ. Seja Homem: A masculinidade desmascarada. São Paulo: Dublinense, 2020.

CONNELL, Robert. Políticas da Masculinidade. Educação e Realidade, Porto Alegre. Vol. 20 (2), 1995.

CONNELL, R. W.; MESSERSCHMIDT, J. W.. Masculinidade hegemônica: repensando o conceito. Rev. Estud. Fem., Florianópolis, v. 21, n. 1, p. 241-282, Apr. 2013. Disponível em http://www.scielo.br/scielo.php?script=sci_arttext\&pid=S0104-

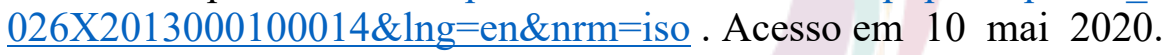

DELPHY, C.; Patriarcado. In: HIRATA, H.; LABORIE, F.; DOARÉ, H.; SENOTIER, D.. Dicionário Crítico do Feminismo. São Paulo: Unesp, 2009. p. 173-178.

DIAS, L; GOMES, L.; Margaridas e masculinidades no futebol. Periódicus, Salvador, n. 13, v.1, p. 233-246. mai.-ago.2020.

Vol. 03, N. 13, Jan. - Abr., 2021 - http://periodicoscientificos.ufmt.br/ojs/index.php/rebeh/index 
FEDERICI, S. Mulheres e caça às bruxas: da Idade Média aos dias atuais. CANDIANI, Heci Regina (trad.). $1^{\circ}$ ed. São Paulo: Boitempo, 2019.

FERRAZ, Lucas. As gravações do caso Robinho na justiça italiana: "A mulher estava completamente bêbada". 2020. Disponível em: https://globoesporte.globo.com/sp/santos-e-regiao/futebol/times/santos/noticia/asgravacoes-do-caso-robinho-na-justica-italiana-a-mulher-estava-completamentebebada.ghtml Acesso em: 28 fev. 2021.

FÓRUM BRASILEIRO DE SEGURANÇA PÚBLICA - FBSP. Anuário brasileiro de segurança pública. São Paulo, 2020.

FRAGOSO, S.; RECUERO, R.; AMARAL, A. Métodos de pesquisa para internet. Porto Alegre: Sulina, 2011.

GASTALDO, E. O complô da torcida: futebol e performances masculinas em bares. In: Horizontes Antropológicos. Porto Alegre, n. 24, p. 107-123, 2005.

GIDDENS, A. A transformação da intimidade: sexualidade, amor \& erotismo nas sociedades modernas. São Paulo: Editora da Universidade Estadual Paulista, 1993.

GIUFRIDA, Bruno. Nenhum jogo, condenação e dívida ajustada: termina a quarta passagem de Robinho pelo Santos. 2021. Disponível em: https:/globoesporte.globo.com/sp/santos-e-regiao/futebol/times/santos/noticia/noticiassantos-fim-contrato-passagem-robinho-condenacao-divida.ghtml Acesso em: $28 \mathrm{fev}$. 2021.

HOLLANDA, B. B.; AZEVEDO, A. L..; QUEIROZ, A. L. Das torcidas jovens às embaixadas de torcedores: uma análise das novas dinâmicas associativas de torcer no futebol brasileiro. Recorde: Revista de História do Esporte, v. 7, n. 1, p. 1-37, 2014.

HOOKS, Bell. O feminismo é para todo mundo: políticas arrebatadoras. 1 ed. Rio de Janeiro: Rosa dos Tempos, 2020.

KIMMEL, M. A produção simultânea de masculinidades hegemônicas e subalternas". Horizontes Antropológicos - Corpo, Doença e Saúde. Porto Alegre. Programa de PósGraduação em Antropologia Social da UFRGS, n. 9, pp. 103-117, 1998.

LAGARDE, M, "El género", fragmento literal: 'La perspectiva de género'. In: Género y feminismo. Desarrollo humano y democracia, Ed. horas y HORAS, España, 1996, pp. 13-38.

LAGARDE, M. Los cautiverios de las mujeres: madresposas, monjas, putas, presas y locas. $4^{\mathrm{a}}$ ed. México: UNAM, 2005. 
LAMOUREUX, D.. Público/Privado. In: HIRATA, H.; LABORIE, F.; DOARÉ, H.; SENOTIER, D.. Dicionário Crítico do Feminismo. São Paulo: Unesp, 2009. p. 208212.

LOURO, G. O corpo educado: pedagogias da sexualidade. Belo Horizonte: Autêntica, 2000 .

MURAD, M. Práticas de violência e mortes de torcedores no futebol brasileiro. Revista USP, (99), 139-152. 2013.

PINTO, M. R.; ALMEIDA, M. B. As Torcidas Queer em campo: a emergência de grupos que questionam a homofobia e o machismo no futebol. Revista Brasileira de Estudos do Lazer, Belo Horizonte, v. 1, n. 2, p. 105-116, ago de 2014.

TIBURI, M. Feminismo em comum: para todas, todes e todos. Rio de Janeiro: Rosa dos

Tempos, 2019.

TOLEDO, L. H. Por Que Xingam os Torcedores de Futebol?. Cadernos De Campo (São Paulo 1991), 3(3), 20-29. 1993.

ZANELLO, V. Saúde mental, gênero e dispositivos: cultura e processos de subjetivação. Curitiba: Appris, 2018.

\section{Offside player! Gender configurations in the repercussion of the Robinho's hiring after sexual violence condemnation}

Abstract: The soccer player Robinho was condemned at first instance in 2017 for sexual violence against a young Albanian woman in Italy. In 2020, when the Santos Futebol Clube team announced his contraction, the case resurfaced and became the subject of debates in the public arena. This article aims to investigate the repercussion of the player's hiring and subsequent suspension of the contract through comments on the club's social network. To this end, Content Analysis was triggered to evaluate 2000 comments made on the club's official Facebook page, from which the four analysis categories were constructed: Perceptions about the soccer player; Perceptions about hiring; Machismo and The dialectic between the Hegemonic Masculinity and the Accomplice Masculinity. Understanding the social interactions involved in the repercussions of this case allowed us to understand the gender configurations present in the Brazilian football arena.

Keywords: Gender; Gender Violence; Sexual Violence; Masculinities; Football. 


\section{Adelantado! Configuraciones de género em repercusión de la contratación de Robinho tras condenación por ompreend sexual}

Resumen: El jugador Robinho fue condenado em primera instancia em 2017 por ompreend sexual contra em joven albanesa em Italia. Em 2020, cuando el equipo Santos Futebol Clube anunció su contracción, el caso volvió a salir a la ompreende y se convirtió em tema de debates em la arena pública. Este artículo tiene como objetivo investigar la repercusión de la contratación del jugador y posterior suspensión del contrato a través de ompreender em la red social del club. Para ello, se activó el Análisis de Contenido para evaluar 2000 comentarios realizados em la página oficial de Facebook del club, a partir de la cual se construyeron las cuatro ompreende de análisis: Percepciones sobre el jugador; Percepciones sobre la contratación; El machismo y la dialéctica entre el ompreender hegemónico y la ompreender cómplice. La comprensión de las ompreender sociales involucradas em las repercusiones de este caso nos permitió ompreender las configuraciones de género presentes em el campo del fútbol brasileño.

Palabras clave: Género; Violencia de género; Violencia sexual; Masculinidades; Fútbol.

Recebido em:09/04/2021

Aceito em: 20/06/2021 